\title{
REHABILITATION OF LOWER LIMB INJURIES
}

\author{
D. WRIGHT, M.C.S.P., Dip.T.P.
}

Withington Hospital, Manchester

The aspect of rehabilitation which is considered to be of paramount importance, and one in which I have particular interest, is that of MOBILITY.

Very rarely, if ever, has a player been declared unfit for play because of a lack of strength. The deciding factor is nearly always a lack of mobility. Medically speaking, one is taking a far greater risk playing rugby with a lack of mobility than ever one can lacking strength, speed or endurance.

Mobility lies within the joints and the limitation to movement at these joints are:

1. Extent of the articular surfaces

2. Tension of antagonistic muscles

3. Tension of ligaments

\section{Contact of soft parts}

With experience one develops an ability to recognise movement which varies from the normal, whether it be limited or excessive. To compare and contrast one can use the opposite limb, or in the case of spinal joints, movement in the opposite direction.

Additional factors which limit movement in the injured joint are:

(a) Pain

(b) Intra-articular causes

(c) Extra-articular causes

(a) PAIN - The mechanism of pain is complex but in the treatment of athletic injuries one is more concerned with the pathological reasons which cause it. Pain is often the yard-stick by which one can measure progress. It is one of the cardinal signs of inflammation and the recognised mode of treatment to deal with it is rest. This, unfortunately, is a dirty word to managers and coaches and surprisingly enough to most players as well. At the same time one has to be realistic about this and rest becomes relative.

(b) INTRA-ARTICULAR CAUSES - These problems have been discussed elsewhere, and it is only the surgeon who can remove obstacles to full mobility either by manipulation or surgery.

(c) EXTRA-ARTICULAR CAUSES - Injury is a form of irritation to the tissues involved and the body's natural response is the attempt to restore the damage to as near normal as possible. This it does by the process of inflammation. A consequence of inflammation is the production to a greater or lesser extent of fibrous tissue. The amount formed often bears a direct relationship to the efficiency of treatment. Fibrous tissue can often be devastating in its effect because it can bind structures together and prevent movement. Its characteristics are that it is very strong and pliable but inelastic.

To treat injuries and to restore injured players back to full fitness one has constantly to consider the implication of allowing fibrous union to take place in spite of its desirability in order that torn structures may become united.

It is in relation to this that the full mobility to joints may be limited.

To illustrate the modern techniques involved two common injuries which limit mobility in the knee-joint are taken as examples.

The "pulled" hamstring. A classical example of this would be a minor rupture at the musculo-tendinous junction of biceps femoris, which presents symptoms of pain on contraction of the muscle against resistance and also pain when a stretch is applied. It is the limitation to stretch which affects mobility and therefore it is vital that we keep this in mind throughout the treatment period. In fact, it is the degree of hamstring stretch which is used as the sole yard-stick of progress. Since pain is a protection mechanism one could not easily apply stretch to the healing muscle tissue without meeting with considerable opposition. Modern techniques provide us with a sound physiological basis which allows us to apply the maximal stretch possible by gaining maximum relaxation. Sherrington's Law's of Successive Induction, i.e. that maximal contraction is followed by maximal relaxation, and that of Reciprocal Inhibition (Eccles and Sherrington, 1931) i.e. that contraction of one group of muscles results in a relaxation of the antagonists, are made use of in a form of exercise therapy known as Proprioceptive Neuro-muscular Facilitation (P.N.F.) (Knott and Voss, 1968). 
The second classical injury to be discussed is a non-specific knee sprain.

It can be assumed that the joint has gone through all the inconvenience of acute inflammation and has reached the stage where some activity can be started. One of the finer points of rehabilitation in this kind of injury is again based on a detail involved in basic anatomy of joints, described in Gray's Anatomy as Accessory Movement, being movement which can only be produced in two ways, namely, passively and against strong resistance. In the case of the knee-joint there is a gliding movement forwards and backwards, and when the joint is semi-flexed from side-to-side.
Until this accessory movement is possible it could well be that the full range of movement in the normal accepted directions of knee movement will be limited. To cope with this problem demands a specialised knowledge of anatomy and also manipulative techniques. It is not suggested that trainers and masseurs dash back to the club and begin to pull and tug at every subsequent joint injury. An awareness of the problem might be sufficient because training schedules could be designed to tax joints sufficiently hard in order that these vital accessory movements are provoked. This is where the game in the Extra " $B$ " team may well serve as a very useful means of obtaining those extra movements which lead to full mobility.

\section{BIBLIOGRAPHY}

1. ECCLES \& SHERRINGTON. Proc. Roy Soc. 1931, 107B, 511, 535, 586, 597.

2. KNOTT, Mgt., B.S., VOSS, Dorothy, B.Ed., 1968, Proprioceptive Neuromuscular Facilitation, Patterns and Techniques. 2nd Edition.

3. GRAY'S ANATOMY, 34th Ed. Syndesmology, p. 492. 1967. 